\title{
Bovine papillomavirus on the scene of crime: is E5 oncogene the only guilty party?
}

\author{
Giuseppe Borzacchiello
}

\begin{abstract}
Bovine papillomaviruses (BPVs) induce hyperplastic and tumoral lesions not only in cows but also in other different animal species. The transforming activity of BPVs is due to its major E5 oncogene. Recent studies have highlighted the role of E5 in cancer development but very little is known about E6 and E7 oncogenes. In this letter we argue for the need of investigating E6 as well as E7 to better understand the role of these two oncogenes during carcinogenesis.
\end{abstract}

Keywords: Bovine papillomavirus, E5, E6, E7

\section{Letter to the editor}

Bovine papillomavirus (BPV) is considered as causative agent of cutaneous and mucosal tumors in its natural host [1]. However, BPV is the only papillomavirus (PV) able to cross infect other species being associated to tumors also in equids [2] buffaloes [3,4], yaks [5], giraffes [6], tapirs [7], zebras and bison [6,8]. BPV has been also largely investigated as animal model to better understand the transforming activity of Pvs. BPV attracted the interest of molecular biologists since it was the first $\mathrm{Pv}$ able to induce transformation in cultured non-epithelial cells; furthermore its genome was the first among PVs to be completely sequenced [9]. Further genetic analysis identified two BPV early (E) genes, E5 and E6, with a direct role in cell transformation [10,11]. E5 was identified as the major BPV oncogene whose transformation activity lies in its binding to and activation of the $\beta$ subunit of the platelet derived growth factor receptor (PDGF $\beta$-r) [12]. Most if not all these observations were derived from in vitro studies.

In the last decade, the role of BPV major oncoprotein E5 in cell transformation has been largely investigated in naturally occurring bovine and equine tumors. Overall, these studies confirmed the pivotal role of E5 in cancer development supporting the role of the virus [13-18]. Interestingly, new facets of BPV infection and

Correspondence: borzacch@unina.it

Department of Veterinary medicine and Animal productions, University of Naples Federico II, Via F. Delpino, 1-80137, Naples, Italy pathogenesis have come to light from recent in vivo studies paving the way for new fields of speculation about PV biology, thus confirming the importance of BPV as animal model [19].

Pv's contribution to tumorigenesis is "paradigmatically" based on the actions of more than one oncogene. Human Pvs (HPVs) E5, E6 and E7 oncoproteins act synergistically disturbing different cellular pathways and in so doing they contribute to initiation and progression of cancer [20]. Moreover, only the activity of both HPV E6 and E7 immortalize primary culture cells [21].

In this regard, among BPV's oncogenes the contribution of the other two oncogenes (E6 and E7) to cancer development is less known. It has been suggested that BPV E7 may cooperate with E5 in inducing cell transformation whereas E6 can downregulate p53 transcriptional activity by interacting with $\mathrm{CBP} / 300$ [22-24]. However, the contribution of BPV to cancer development, according to "PV's paradigm", may not result only from E5 oncoprotein's activity [25]. More and more studies should investigate BPV E6 and E7 to understand their possible role in animal cancer development in order to better define the molecular scenario of bovine and equids tumors. Moreover, from a comparative point of view, further investigations on BPVs will still give a contribute to discovering new aspects of PV's biology and pathology. 


\section{Competing interests}

The author declares that he has no competing interests.

Received: 10 May 2013 Accepted: 1 July 2013

Published: 5 July 2013

\section{References}

1. Borzacchiello G, Roperto F: Bovine papillomaviruses, papillomas and cancer in cattle. Vet Res 2008, 39(5):45.

2. Nasir L, Campo MS: Bovine papillomaviruses: their role in the aetiology of cutaneous tumours of bovids and equids. Vet Dermato/ 2008, 19(5):243-254.

3. Silvestre O, Borzacchiello G, Nava D, lovane G, Russo V, Vecchio D, D'Ausilio F, Gault EA, Campo MS, Paciello O: Bovine papillomavirus type 1 DNA and E5 oncoprotein expression in water buffalo fibropapillomas. Vet Pathol 2009, 46(4):636-641.

4. Pangty $K$, Singh S, Goswami R, Saikumar G, Somvanshi R: Detection of BPV1 and -2 and quantification of BPV-1 by real-time PCR in cutaneous warts in cattle and buffaloes. Transbound Emerg Dis 2010, 57(3):185-196.

5. Bam J, Kumar P, Leishangthem GD, Saikia A, Somvanshi R: Spontaneous Cutaneous Papillomatosis in Yaks and Detection and Quantification of Bovine Papillomavirus -1 and -2. Transbound Emerg Dis 2012. doi:10.1111/ j.1865-1682.2012.01361.x. [Epub ahead of print].

6. van Dyk E, Oosthuizen MC, Bosman AM, Nel PJ, Zimmerman D, Venter EH: Detection of bovine papillomavirus DNA in sarcoid-affected and healthy free-roaming zebra (Equus zebra) populations in South Africa. $J$ Virol Methods 2009, 158(1-2):141-151.

7. Kidney BA, Berrocal A: Sarcoids in two captive tapirs (Tapirus bairdii): clinical, pathological and molecular study. Vet Dermato/ 2008, 19(6):380-384.

8. Literak I, Tomita Y, Ogawa T, Shirasawa H, Smid B, Novotny L, Adamec M Papillomatosis in a European bison. J Wildl Dis 2006, 42(1):149-153.

9. Chen EY, Howley PM, Levinson AD, Seeburg PH: The primary structure and genetic organization of the bovine papillomavirus type 1 genome. Nature 1982, 299(5883):529-534.

10. Groff $D E$, Lancaster WD: Genetic analysis of the 3 ' early region transformation and replication functions of bovine papillomavirus type 1. Virology 1986, 150(1):221-230.

11. Yang YC, Okayama H, Howley PM: Bovine papillomavirus contains multiple transforming genes. Proc Natl Acad Sci USA 1985, 82(4):1030-1034

12. Petti L, Nilson LA, DiMaio D: Activation of the platelet-derived growth factor receptor by the bovine papillomavirus E5 transforming protein EMBO J 1991, 10(4):845-855.

13. Borzacchiello G: Presence of bovine papillomavirus type 2 DNA and expression of the viral oncoprotein E5 in naturally occurring urinary bladder tumours in cows. J Gen Virol 2003, 84(11):2921-2926.

14. Borzacchiello G, Russo V, Gentile F, Roperto F, Venuti A, Nitsch L, Campo MS, Roperto S: Bovine papillomavirus E5 oncoprotein binds to the activated form of the platelet-derived growth factor beta receptor in naturally occurring bovine urinary bladder tumours. Oncogene 2006 25(8):1251-1260.

15. Borzacchiello G, Russo V, Spoleto C, Roperto S, Balcos L, Rizzo C, Venuti A, Roperto F: Bovine papillomavirus type-2 DNA and expression of E5 and E7 oncoproteins in vascular tumours of the urinary bladder in cattle. Cancer Lett 2007, 250(1):82-91.

16. Venuti A, Paolini F, Nasir L, Corteggio A, Roperto S, Campo MS, Borzacchiello G: Papillomavirus E5: the smallest oncoprotein with many functions. Mol Cancer 2011, 10(1):140.

17. Borzacchiello G, Corteggio A: Equine Sarcoid: State of the Art. Ippologia 2009, 20(4):7-14.

18. Silva MA, Altamura G, Corteggio A, Roperto F, Bocaneti F, Velescu E, Freitas AC, Carvalho CC, Cavalcanti KP, Borzacchiello G: Expression of connexin 26 and bovine papillomavirus E5 in cutaneous fibropapillomas of cattle. Vet J 2013, 195(3):337-343.

19. Borzacchiello G, Roperto F, Nasir L, Campo MS: Human papillomavirus research: do we still need animal models? Int J Cancer 2009, 125(3):739-740.

20. Moody CA, Laimins LA: Human papillomavirus oncoproteins: pathways to transformation. Nat Rev Cancer 2010, 10(8):550-560.
21. Munger K, Phelps WC, Bubb V, Howley PM, Schlegel R: The E6 and E7 genes of the human papillomavirus type 16 together are necessary and sufficient for transformation of primary human keratinocytes. J Virol 1989, 63(10):4417-4421

22. Bohl J, Hull B, Vande Pol SB: Cooperative transformation and coexpression of bovine papillomavirus type 1 E5 and E7 proteins. J Virol 2001, 75(1):513-521

23. DeMasi J, Huh KW, Nakatani Y, Munger K, Howley PM: Bovine papillomavirus E7 transformation function correlates with cellular p600 protein binding. Proc Natl Acad Sci USA 2005, 102(32):11486-11491.

24. Zimmermann H, Koh CH, Degenkolbe R, O'Connor MJ, Muller A, Steger G, Chen JJ, Lui Y, Androphy E, Bernard HU: Interaction with CBP/p300 enables the bovine papillomavirus type $1 \mathrm{E} 6$ oncoprotein to downregulate CBP/p300-mediated transactivation by p53. J Gen Virol 2000, 81(Pt 11):2617-2623.

25. Corteggio A, Altamura G, Roperto F, Borzacchiello G: Bovine papillomavirus E5 and E7 oncoproteins in naturally occurring tumors: are two better than one? Infectious agents and cancer 2013, 8(1):1.

doi:10.1186/1750-9378-8-26

Cite this article as: Borzacchiello: Bovine papillomavirus on the scene of crime: is E5 oncogene the only guilty party? Infectious Agents and Cancer 2013 8:26.

\section{Submit your next manuscript to BioMed Central and take full advantage of:}

- Convenient online submission

- Thorough peer review

- No space constraints or color figure charges

- Immediate publication on acceptance

- Inclusion in PubMed, CAS, Scopus and Google Scholar

- Research which is freely available for redistribution 